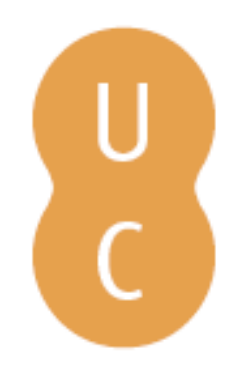

\title{
pommalina
}

\section{As três religiões do livro}

Autor(es): $\quad$ Mattoso, José

Publicado por: Imprensa da Universidade de Coimbra

URL

persistente: URI:http://hdl.handle.net/10316.2/30090

DOI: $\quad$ DOI:http://dx.doi.org/10.14195/978-989-26-0310-0_9

Accessed : $\quad$ 26-Apr-2023 11:49:23

A navegação consulta e descarregamento dos títulos inseridos nas Bibliotecas Digitais UC Digitalis, UC Pombalina e UC Impactum, pressupõem a aceitação plena e sem reservas dos Termos e Condições de Uso destas Bibliotecas Digitais, disponíveis em https://digitalis.uc.pt/pt-pt/termos.

Conforme exposto nos referidos Termos e Condições de Uso, o descarregamento de títulos de acesso restrito requer uma licença válida de autorização devendo o utilizador aceder ao(s) documento(s) a partir de um endereço de IP da instituição detentora da supramencionada licença.

Ao utilizador é apenas permitido o descarregamento para uso pessoal, pelo que o emprego do(s) título(s) descarregado(s) para outro fim, designadamente comercial, carece de autorização do respetivo autor ou editor da obra.

Na medida em que todas as obras da UC Digitalis se encontram protegidas pelo Código do Direito de Autor e Direitos Conexos e demais legislação aplicável, toda a cópia, parcial ou total, deste documento, nos casos em que é legalmente admitida, deverá conter ou fazer-se acompanhar por este aviso.

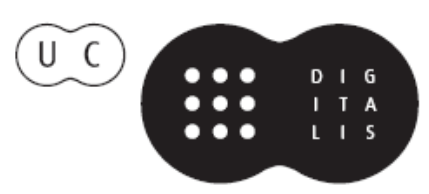




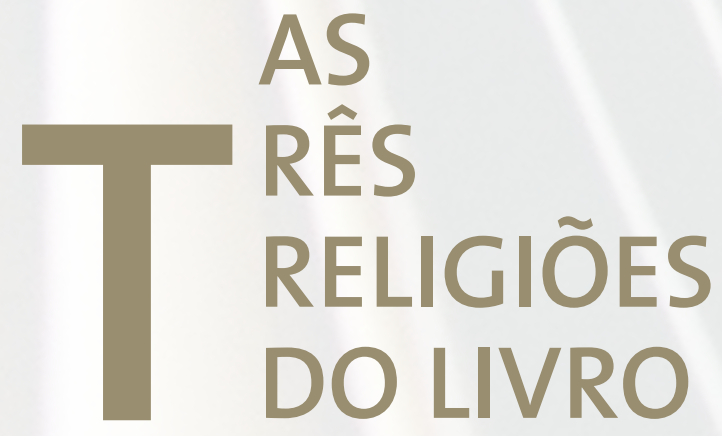

Anselmo Borges

João Gouveia Monteiro

COORDENAÇÃO 
José Mattoso 25

\section{AS TRÊS RELIGIÕ ES DO LIVRO}

Não podendo participar pessoalmente neste colóquio sobre as três religiões do livro, queria, em todo o caso, contribuir de alguma maneira para que ele possa atingir os seus objectivos, que me parecem tão importantes e oportunos. Com efeito, o diálogo inter-religioso tornou-se, em virtude da gravidade dos conflitos civilizacionais que agitam a nossa época, um processo da maior importância para tentar atenuar as suas ameaçadoras consequências. Depois das duas mesas-redondas de hoje, consagradas à discussão de problemas de carácter doutrinal, em torno das relações entre o monoteísmo e o fundamentalismo, e acerca das diferenças e contactos entre as religiões místicas e as religiões proféticas, queria propor uma breve reflexão sobre o que a história do Ocidente europeu e, sobretudo, a história da Península Ibérica nos diz acerca dos contactos culturais entre o Cristianismo, o Judaísmo e o Islamismo. Esta incursão no passado parece-me poder servir para mostrar que o diálogo inter-religioso, apesar de, na nossa época, se ter tornado tão difícil, devido à violência e às dimensões que os conflitos religiosos têm atingido, não é impossível nem inútil. Com efeito, além das razões que o justificam em si mesmo, convém lembrar que este diálogo se insere num movimento de dimensões universais e de teor cada vez mais intenso e diversificado. Refiro-me ao movimento de promoção dos contactos entre culturas, ao qual, desde há alguns anos, a UNESCO tem procurado dar todo o apoio possível. Parece-me, portanto, que, longe de nos deixarmos abater pelo pessimismo e o desânimo suscitados por constantes notícias

25 Historiador. 
acerca de trágicos acontecimentos resultantes de antagonismos religiosos nas mais diversas regiões do globo, merece a pena cultivar cuidadosamente o diálogo e prevenir a violência. Com efeito, se a História regista toda a espécie de guerras, destruições e violências em nome dos antagonismos religiosos, guarda também a memória de contactos pacíficos, de trocas fecundas e de sínteses felizes. Merece a pena recordá-los.

Queria mencionar, em primeiro lugar, o facto de os regimes políticos muçulmanos terem admitido a permanência de comunidades cristãs no seu território depois de implantados na Hispânia no princípio do século viII. Depois da invasão da Península Ibérica pelos muçulmanos, os cristãos puderam manter as suas igrejas, o seu culto e a sua hierarquia, mediante o pagamento de um imposto. Chegaram até nós informações precisas acerca de episódios que marcaram a existência destas comunidades, das suas condições de vida, de alguns dos personagens que então se notabilizaram e de alguns dos seus escritos. Se a sua condição se veio a deteriorar nos séculos XI e XII, com a substituição dos soberanos omíadas pelos regimes almorávida e almóada, não é menos verdade que a convivência predominantemente pacífica entre cristãos e muçulmanos se traduziu por uma cultura própria: a cultura moçárabe. O facto de ela se exprimir por meio da língua árabe mostra, só por si, que os seus protagonistas souberam integrar elementos quer de origem latina, quer de origem árabe, e que a religião não impediu as trocas nem os contactos de uns com os outros. Com efeito, produziu resultados extremamente positivos e originais nos domínios da literatura, da arte, da ciência, da técnica e mesmo da filosofia e da mística. Depois de três ou quatro séculos de convívio, a maioria dos moçárabes fiéis à religião que professavam acabou por emigrar para território cristão, levando consigo muitos valores adquiridos no contacto com os muçulmanos. Por outro lado, muitos cristãos converteram-se ao islamismo, mas formaram comunidades com a sua identidade peculiar - os muladís - igualmente caracterizadas pela assimilação de elementos das duas culturas. Foi neste contexto que a sociedade cristã dos reinos do Norte - sobretudo Leão, Castela e Aragão - recebeu muitos contributos civilizacionais de origem islâmica que ainda hoje se podem verificar através da grande quantidade de vocábulos árabes preservados tanto pelo português como pelo castelhano. Estes vocábulos 
testemunham os benefícios civilizacionais resultantes do contacto cultural, sobretudo nas áreas da tecnologia agrícola, das instituições administrativas e da organização militar. A história da arte também assinala formas oriundas do sul moçárabe ou islâmico na arquitectura, na escultura e nas artes decorativas.

Para o que pretendemos, porém, isto é, para, em termos gerais, mostrar a necessidade dos contactos entre adeptos de religiões diferentes, não basta reconhecer os seus resultados positivos em termos civilizacionais. É preciso sublinhar, mais concretamente, a necessidade da compreensão mútua em termos doutrinais. Deste ponto de vista, tem particular interesse mencionar a influência que a filosofia árabe dos séculos XI a XIII exerceu sobre a escolástica medieval, tanto no domínio da filosofia como da teologia. Com efeito, foi por intermédio da recepção de traduções latinas de obras filosóficas árabes de inspiração neo-platónica ou aristotélica, que a primeira escolástica cristã reencontrou a racionalidade do pensamento grego. É enorme a dívida da escolástica medieval para com a transmissão da filosofia grega por intermédio das traduções e dos comentários árabes, quer do ponto de vista do método intelectual, graças à renovação da lógica e da dialéctica, quer do ponto de vista da reflexão física e metafísica, em virtude da discussão das doutrinas platónicas e aristotélicas. Apesar da oposição religiosa entre cristãos e muçulmanos, as escolas das catedrais e as universidades, sobretudo a universidade de Paris, estudaram com cuidado as obras de autores como al-Farabi, Avicena, Averrois e muitos outros autores árabes, traduzidos para o latim quer na Sicília, quer em Toledo e em Sevilha. Apesar das responsabilidades religiosas no domínio da defesa da fé, atribuídas aos soberanos católicos pelo clero, em geral, e pelo papa, em particular, Afonso X “o Sábio", rei de Leão e Castela, e Frederico II, imperador da Alemanha e rei da Sicília, não deixaram de promover a preservação de muitas obras típicas da literatura e do pensamento árabe e de contribuir para a sua difusão no mundo latino, por meio de traduções em língua vulgar e em latim. Desempenharam, pois, uma função da maior importância no domínio do encontro de culturas. A ortodoxia religiosa não os impediu de descobrir os valores contidos em textos oriundos de países que professavam outra fé e que combatiam pelas armas. 
Estes contactos não foram apenas fenómenos difusos. Revestiram aspectos muito concretos. Para me cingir apenas a temas filosóficos, com incidências directas sobre as doutrinas religiosas, posso referir aqui a influência de conceitos tais como a distinção real entre essência e existência, princípio que S. Tomás de Aquino recebeu de al-Farabi, ou as noções de matéria e forma e de acto e potência, ou ainda a distinção entre os quatro tipos de causas e entre as dez categorias por meio das quais se define o ser, doutrinas que o mesmo S. Tomás recebeu de Aristóteles. Neste último caso, S. Tomás recorreu a traduções latinas recentes feitas directamente do grego. Mas a sua predilecção por Aristóteles tinha, antes disso, sido preparada pela difusão anterior das traduções latinas através do árabe e, sobretudo, pela leitura dos comentários de Avicena e Averrois. De resto, na primeira escolástica, não se verificou apenas um fenómeno de recepção intelectual. Algumas das doutrinas filosóficas de Averrois, adoptadas, por exemplo, por Siger de Brabante, foram refutadas por S. Tomás como inconciliáveis com o cristianismo. A recepção da filosofia árabe no Ocidente não foi, pois, meramente passiva; não excluía a reflexão crítica nem a busca da coerência interna dos sistemas interpretativos.

Estes factos, muito estudados pelos historiadores ocidentais da filosofia medieval, mostram claramente que os pensadores dessa época não viram na diferença de religião nenhum obstáculo ao estudo e compreensão do pensamento alheio. Esta atitude implica, obviamente, admiração e respeito pela cultura dos adversários religiosos e capacidade de compreensão das suas obras. Como é evidente, as duas sociedades continuaram separadas e mesmo antagónicas; procuraram apropriar-se de fiéis, riquezas e territórios uma da outra; mas não eram norteadas por propósitos de aniquilação do adversário.

Com a recuperação cristã do território peninsular que tinha estado sob o domínio muçulmano entre os séculos VIII e XV, a situação das minorias religiosas inverteu-se. Às comunidades moçárabes em território islâmico corresponderam, desde a conquista de Toledo, em 1085, por Afonso VI, rei de Leão e Castela, as minorias sarracenas em território cristão. A reconquista cristã praticou muitas violências e até genocídios locais, mas em geral deixou partir os vencidos das suas cidades e acantonou os que queriam ficar, 
ou que não podiam partir, em bairros chamados «mourarias». Também estas desempenharam o seu papel como factores de diálogo cultural. Os soberanos peninsulares impediram a redução à escravatura da totalidade dos mouros que ficaram nas áreas conquistadas. Conscientes das vantagens económicas decorrentes do imposto que eles tinham de pagar, e do exercício de profissões artesanais em que eram peritos, protegeram-nos e definiram o seu estatuto por meio de forais, como o que Afonso Henriques concedeu aos mouros forros de Lisboa, Almada, Palmela e Alcácer, em 1170, e Afonso III aos mouros forros de Évora, em 1273. Os mouros ficaram, assim, em condições análogas àquelas em que os moçárabes tinham estado em território muçulmano nos séculos anteriores. Foi-lhes permitido manter os seus costumes, praticar o seu culto, ter as suas mesquitas e obedecer aos seus líderes religiosos.

Em Portugal, as minorias mouras foram sendo progressivamente assimiladas, acabando por perder a sua identidade no princípio do século XVI. Em Espanha, porém, mantiveram-na com maior persistência, como se depreende do próprio nome pelo qual eram conhecidos: mudéjares. Revelaram-na especialmente no trabalho construtivo e nas artes decorativas, criando um estilo próprio.

O sistema adoptado pelos árabes, de reconhecer a minorias religiosas o direito à constituição de comunidades diferenciadas do conjunto social, deu lugar à formação de judiarias. Os judeus beneficiaram também de uma certa liberdade religiosa, mediante o pagamento de um tributo. Este facto não impediu uma sucessão variada de situações de tolerância e de perseguição, quer por parte de autoridades cristãs, quer de autoridades muçulmanas. No primeiro caso, a um período em que predominou a convivência indiferenciada, sucedeu, a partir do século xiII, o agrupamento dos judeus em guetos ou bairros fechados, o que impedia ou dificultava os contactos. O facto de um certo número de judeus se terem especializado em actividades relacionadas com a economia monetária e com a prática da medicina e da ourivesaria aproximou alguns deles dos soberanos, que os escolheram como cobradores de impostos, conselheiros financeiros ou administradores territoriais e, por conseguinte, como agentes da centralização do Estado. Este facto tanto provocou, em certos casos, os contactos entre a cultura 
judaica e a cultura cristã protagonizados pelos referidos agentes, como, noutros casos, actos de fanatismo desencadeados pelas vítimas da opressão económica que lhes atribuíam. Durante a baixa Idade Média o isolamento físico dos judeus obrigados a morar em guetos acentuou a sua coesão e provocou fenómenos de atribuição de caracteres identitários, muitos deles imaginários, acabando por provocar pogroms sangrentos e, por fim, a expulsão em massa de Aragão e Castela, pelos Reis Católicos, em 1492, e de Portugal, por D. Manuel, em 1496.

Apesar destes obstáculos, não se podem esquecer os contactos culturais entre judeus e cristãos que se verificaram durante a Idade Média. Podem-se concretizar claramente na recepção que alguns filósofos judeus tiveram entre os teólogos escolásticos, entre eles Ibn Gabirol e Maimónides. O primeiro, que viveu no século XI, procurou conciliar a doutrina platónica com a concepção bíblica de Deus como criador do mundo a partir do nada. Esta posição foi também partilhada pelo célebre Maimónides (século XII), que exerceu uma grande influência sobre o pensamento cristão medieval, não só por aprofundar a doutrina de Deus como criador do mundo, mas também pela sua justificação do messianismo, da ressurreição e da função de Deus como juiz das acções humanas, isto é, como recompensador dos bons e castigador dos maus. Como é evidente, estas doutrinas aproximam-no claramente do pensamento cristão. Mas os contactos entre cristãos e judeus não se reduziram ao campo da filosofia e teologia: situaram-se também no domínio da poesia, como testemunham os poemas de Abraão Ibn Ezra, ou da historiografia e da geografia, através das narrativas de viagem de Benjamim de Tudela, cujos relatos foram traduzidos em castelhano, sem contar com outras obras científicas nos domínios da medicina, da botânica, da astronomia e da matemática.

Podemos dizer, portanto, que, durante a Idade Média, a diferença religiosa não impediu os contactos culturais e o reconhecimento dos valores literários, científicos, filosóficos e artísticos criados por adeptos de cada uma das religiões do livro. O exemplos que demos mostram-no claramente. Poder-se-ia pensar que se situam apenas em dois sectores: as trocas no domínio das práticas (agricultura, artesanato, artes decorativas, administração, etc.) e no domínio da arte e da filosofia. Creio, porém, que a tolerância, e 
até o respeito, pela crença dos fiéis de religiões alheias ia mais fundo do que isso. É o que me parece dever deduzir do princípio definido por Afonso X "o Sábio", no seu código jurídico intitulado As Partidas. Com efeito, no conjunto das leis que estabelece a propósito dos judeus, diz o seguinte:

Visto que a sinagoga é a casa onde se louva o nome de Deus, defendemos (isto é, proibimos) que nenhum cristão ouse quebrantá-la, nem tirar, nem tomar dela coisa alguma por força, excepto se algum malfeitor se acolher a ela, porque este pode-se prender por força e levá-lo perante a justiça. Os cristãos também não podem pôr nela animais, nem pousar nela, nem embargar os judeus, enquanto nela estiverem em oração.

Como é evidente, esta formulação, longe de considerar o culto judaico como ofensa a Deus, supõe o maior respeito pelo acto religioso que ele representa e, até, a identificação do Deus de Israel com o Deus dos cristãos. O mesmo respeito transparece na lei seguinte, acerca do sábado:

Sábado é o dia em que os judeus fazem suas orações e ficam em descanso nas suas casas e não compram, nem entram em pleito. E como eles são obrigados a guardar tal dia segundo as suas leis, por isso mandamos que nenhum juiz oprima nem obrigue os judeus ao sábado para os trazer a juízo por dívidas, nem os prenda nem os oprima em tal dia. Bastam os outros dias da semana para os constranger.

No mesmo código, embora se favoreça a conversão dos judeus ao cristianismo, o rei recomenda que ela se faça por meio dos "bons exemplos e ditos da Sagrada Escritura, porque nosso Senhor Deus não quer nem ama serviço que seja feito por força."

É claro que estas leis não impedem o mesmo Afonso X de promulgar também preceitos que favorecem a conversão dos judeus ao cristianismo, que assimilam a hereges os cristãos que se convertem ao judaísmo, e que reserva para juízes cristãos os pleitos entre judeus e cristãos.

Não é preciso lembrar o abismo que opõe estes testemunhos de tolerância e de humanidade à teoria e à prática seguidas pela Inquisição portuguesa 
e espanhola desde meados do século XVI. Não temos, pois, o direito de apresentar a nossa história como um exemplo de tolerância religiosa. Apesar disso, não posso deixar de invocar aqui as opiniões de um dos mais conceituados especialistas actuais da história judaica, o Prof. Carsten Wilke, investigador no Instituto Steinheim de História Judaica Alemã, em Duisburg (Alemanha). Na sua obra, recentemente traduzida em português com o título de História dos Judeus portugueses, diz que, durante a Idade Média, "Portugal garantia aos judeus mais protecção e segurança que qualquer outro país europeu». Apesar da "retracção" que se seguiu à conversão forçada em 1497, e que promoveu a "clandestinidade precária" dos que ficaram e a dispersão dos que saíram pelos quatro cantos do mundo, os judeus de origem portuguesa não perderam totalmente a sua identidade. A dispersão, segundo Wilke, foi "confortada por um judaísmo reinventado» do qual resultou aquilo a que ele chama "uma consciência judaico-portuguesa» que "forneceu um dos exemplos mais acabados de um particularismo étnico no seio do povo judaico». Manifesta-se, por um lado, na evocação de uma mítica era de liberdade reportada pelos judeus sefarditas à situação anterior à expulsão, e, por outro lado, na secular resistência dos marranos de Belmonte, que só se compreende em virtude de uma singular conjugação de efectiva tolerância por parte da comunidade cristã local com uma extraordinária fidelidade oculta por parte dos cristãos novos ao seu culto ancestral.

Enfim, para que a memória incómoda da Inquisição nos não envergonhe excessivamente, queria evocar aqui a figura de Aristides de Sousa Mendes que, de alguma maneira, nos reconcilia também com os aspectos mais negros do nosso passado. Estes dois exemplos da nossa história apresentam-se como os dois braços em que o Y se divide e que Santo Isidoro de Sevilha apresenta como o símbolo da vida humana. Chegados a um certo ponto, a uma encruzilhada da nossa peregrinação terrestre, temos de escolher o nosso caminho: ou pela direita, ou pela esquerda. A escolha é obrigatória. Entre a tolerância e a intolerância, não há conciliação possível. Deus, porém, é um só. O mesmo para judeus, cristãos e muçulmanos. Só Ele tem direito de julgar, e de salvar ou condenar. Querer tomar o seu lugar e matar em seu nome é a pior das blasfémias. A história da humanidade está cheia de blasfémias. Já é tempo de resgatarmos aquelas que os nossos antepassados cometeram. 